Mark Rudow MD, Anne B. Hill MB BCH FFarcs, Norman W. Thompson MD, Jay S. Finch MD

\title{
Helium-oxygen mixtures in airway obstruction due to thyroid carcinoma
}

The management of a patient with severe airway obstruction secondary to a thyroid mass is reported. When breathing room air the patient appeared in severe respiratory distress but when inspiring 22 per cent oxygen in helium she reported almost instantaneous relief and there was a marked decrease in respiratory rate, and increase in tidal volume and arterial oxygen tension. This improvement was to be expected because in situations where turbulent flow predominates a decrease in the density of inspired gases will result in an increase in flow rates. Contrary to established dogma a marked improvement was sustained when the patient was breathing 50 per cent oxygen in helium. The concentraton of oxygen in helium was adjusted to obtain subjective relief for the patient in conjunction with adequate oxygenation.

Severe airway obstruction is an uncommon complication of thyroid disease. In such cases, during general anaesthesia, mechanical difficulties in securing and maintaining the airway must be anticipated; in addition there is the potential risk of acute tracheal collapse secondary to tracheomalacia. The addition of helium to the inspired gases decreases the density of these gases, thereby increasing flow rates through obstructed areas with the characteris-

\section{Key words}

COMPLICATIONS: airway obstruction, tracheal compression; GASES, NONANAESTHETIC: helium.

From the University of Michigan Medical Center, Departments of Anesthesiology and Surgery, Ann Arbor, Michigan.

Address correspondence to: Dr. Anne B. Hill, Departments of Anesthesiology, University of Michigan Hospital, Room IG323, Box 0048, Ann Arbor, Michigan 48109 . tics of an orifice. We present a case of severe airway obstruction secondary to thyroid carcinoma and discuss our pre- and intraoperative management.

\section{Case history}

A seventy-eight year old female was transferred from another hospital with a diagnosis of airway obstruction secondary to a neck mass extending into the mediastinum and multiple pulmonary metastases. She had a six- to eight-week history of progressive dyspnoea, of such severity she had been unable to sleep for one week, had to remain in an upright position and on occasions elevate her arms. Significant past history revealed a left radical mastectomy approximately thirteen years previously, and removal of the right eye for melanoma some time prior to the mastectomy.

The patient was seen immediately on admission. Physical examination revealed a frail, tired woman, weighing approximately $37 \mathrm{~kg}$, sitting upright and using the accessory muscles of respiration. Respiratory rate was $22 / \mathrm{min}$ at rest. On being asked to count the patient had to inspire between each digit. A firm, fixed mass was felt in the midline, at the inferior border of the thyroid cartilage, extending substernally past the supra-sternal notch. There was harsh stridor on both inspiration and expiration, otherwise the lungs were clear to auscultation. The chest $x$-ray showed a large superior mediastinal mass, evidence of a previous left mastectomy and bilateral pulmonary nodular changes, probably metastatic in origin. Thyroid ultrasound revealed a solid mass.

Computerized axial tomography showed a large mass at the thoracic inlet extending caudally to just above the level of the arch of the aorta. The upper border could not be identified as the patient's dysnoea prevented the necessary positioning. The mass was seen to compress the trachea markedly, 


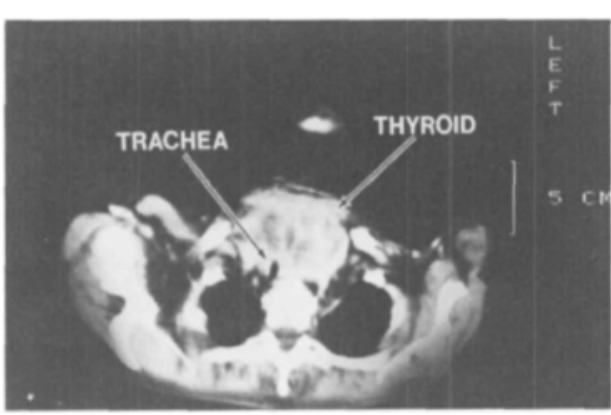

FIGURE 1 Computerized axialial tomogram scan showing the greatly enlarged thyroid compressing and deviating the trachea to the right.

deviating it to the right (Figure 1). Tidal volume and forced vital capacity were measured with a Wright's respirometer and arterial blood gas analysis performed when the patient was breathing room air (Table I). The patient was unable to register a reading on a peak flow meter.

In view of the patient's near exhaustion, emergency surgery was contemplated to relieve the obstruction. In the hope that the respiratory distress was due to constriction of the trachea by the thyroid mass, an immediate trial of oxygen therapy with helium as a carrier gas was commenced. A cylinder of helium:oxygen (80\%:20\%) was connected to a nebulizer and oxygen added from the piped supply to achieve a concentration of helium 78 per cent oxygen 22 per cent as recorded by a paramagnetic oxygen analyzer. This mixture was delivered via a tight-fitting mask. The patient spontaneously reported almost instant relief, assumed a semirecumbent position and her respiratory rate dropped to $15 / \mathrm{min}$. After thirty minutes of equilibration, tidal volume and arterial oxygenation showed marked improvement. The oxygen concentration

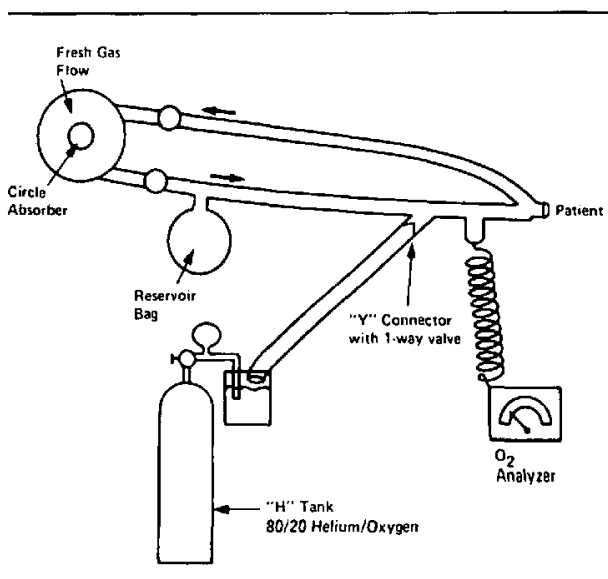

FIGURE 2 Diagram of anaesthetic circuit to which helium oxygen is added. An oxygen analyzer is placed downstream.

was increased to 50 per cent in helium and the tests repeated approximately thirty minutes later (Table I). She was then maintained on 22 per cent oxygen in helium overnight and her family reported that she slept for the first time in a week.

The following morning she was taken to the operating room for a thyroidectomy. Helium was attached to the anaesthetic circuit via a " $Y$ " connector, and an oxygen analyzer was inserted downstream and flows adjusted to achieve the desired oxygen concentration (Figure 2). The surgical team, sternal saw, tracheostomy set, rigid bronchoscope, and various sizes of endotracheal tubes were in readiness. The patient was breathing oxygen 22 per cent in helium and was comfortable. A bilateral superior laryngeal nerve block was performed and her oropharynx was sprayed with lidocaine four per cent. Laryngoscopy was performed with the patient in a sitting position. The vocal cords were visualized easily and the tip of a $7.0 \mathrm{~mm}$ armoured tube

TABLE I Measured variables

\begin{tabular}{llllll}
\hline Inspired gases & $\begin{array}{l}\text { Tidal volume } \\
(\mathrm{ml})\end{array}$ & $\begin{array}{l}\text { Forced vital } \\
\text { capacity }(\mathrm{ml})\end{array}$ & $\mathrm{pH}$ & $\mathrm{PaO}_{2}(\mathrm{kPa})$ & $\mathrm{PaCO}_{2}(\mathrm{kPa})$ \\
\hline Room air & 150 & 800 & 7.44 & 8.4 & 5.2 \\
$\begin{array}{l}\text { Helium: } \mathrm{O}_{2} \\
\text { 78:22 }\end{array}$ & 340 & 800 & 7.45 & 13.9 & 5.2 \\
$\begin{array}{l}\text { Helium: } \mathrm{O}_{2} \\
\text { 50:50 }\end{array}$ & 300 & 750 & 7.43 & 40 & 5.2 \\
\hline
\end{tabular}


TABLE II Critical volume flow rates of air: maximum laminar flow rate

\begin{tabular}{lrrrrrr}
\hline $\begin{array}{l}\text { Diameter } \\
\text { Flow rates } \\
\mathrm{L} \cdot \mathrm{min}^{-1}\end{array}$ & .25 & 0.5 & .75 & 1.0 & 1.5 & 2.0 \\
\hline
\end{tabular}

Reproduced from "Physics For Anaesthetists" by MacIntosh R, Mushin WW, Epstein AG, 3rd ed. Oxford, Blackwell 1963 with permisson of publisher.

was passed, ventilation was controlled, and bilateral breath sounds confirmed. Anaesthesia was then induced with thiamylal, $160 \mathrm{mg}$, and relaxation achieved with pancuronium, $4 \mathrm{mg}$. The endotracheal tube was then advanced with a gentle rotating movement, bilateral breath sounds reconfirmed and the endotracheal tube firmly secured. Anaesthesia was maintained with enflurane, nitrous oxide and oxygen; ventilation was controlled. The thyroidectomy was uneventful, the compressed area of the trachea was obvious but the cartilaginous rings appeared intact.

On completion of surgery the trachea was extubated, without complication. The following day the patient was lying flat, conversing normally without evidence of vocal cord or tracheal damage. The remainder of the hospital course was uneventful.

\section{Discussion}

Although the physics regarding laminar versus turbulent flow is well known, it is unusual to be presented with a case in which the addition of helium to oxygen would be beneficial.

Under normal circumstances gas flow in the large airways is laminar and:

flow is proportional to $\frac{\text { the pressure gradient } \times \text { radius }^{4}}{\text { viscosity } \times \text { length of tube }}$
If flow rate exceeds a certain critical value, laminar flow is replaced by turbulent flow and this critical rate of flow varies directly with the internal diameter of the tube (Table II). ${ }^{1}$ The laws relating the transition from laminar to turbulent flow were elucidated by Reynolds, and Reynolds critical number is the factor relating critical velocity to pipe diameter, density and viscosity. ${ }^{2}$ Flow through an orifice is always partly turbulent and under these conditions flow rate will vary inversely with the square root of the density. This contrasts with conditions of laminar flow when rate will vary inversely with viscosity. The viscosities of helium and oxygen are very similar with the result that flow rates will be similar under conditions of laminar flow, but their densities are very different, with the result that helium will flow almost three times faster across an orifice than will oxygen (Table III). The marked improvement in this patient on inspiring mixtures less dense than air confirmed that laminar flow had been replaced by turbulent flow.

This patient was able to maintain a normal $\mathrm{PaCO}_{2}$ on air but only by increasing the work of breathing. Respiratory rate was $22 / \mathrm{min}$, tidal volume $150 \mathrm{ml}$ and the accessory muscles of respiration were in use. On inspiring oxygen 22 per cent in helium, tidal volume increased to $340 \mathrm{ml}$ and respiratory rate dropped to $15 / \mathrm{min}$. These values are consistent with Radford's nomogram for predicting basal tidal volume to maintain normocarbia at varying respiratory rates. ${ }^{3}$ Benumof states that the use of helium/ oxygen mixtures prevent the use of high inspired oxygen concentration ${ }^{4}$ and Table III would appear to support this dictum. This patient remained as improved (for a short period of time) on 50 per cent helium as on 80 per cent helium and there have been other reports ${ }^{5,6}$ of the beneficial effects of helium in concentrations below 80 per cent. We maintained

TABLE III Densities and relative gas flow rates of oxygen air and helium

\begin{tabular}{llllll}
\hline & & & & & $\begin{array}{l}\text { Relative air flow rate } \\
\text { (air assigned an } \\
\text { arbitrary value of 1.00) }\end{array}$ \\
\hline Oxygen & 100 & 1.429 & 1.182 & 0.846 & 0.96 \\
Air & 100 & 1.293 & 1.135 & 0.881 & 1.00 \\
Helium & 100 & 0.179 & 0.423 & 2.364 & 2.68 \\
He-oxygen & $20 / 80$ & 1.178 & 1.085 & 0.922 & 1.048 \\
He-oxygen & $60 / 40$ & 0.678 & 0.823 & 1.215 & 1.381 \\
He-oxygen & $80 / 20$ & 0.429 & 0.655 & 1.527 & 1.73 \\
\hline
\end{tabular}


the patient on 22 per cent oxygen in helium as oxygenation was adequate when breathing this mixture.

The patient was unable to register a reading on a peak flow meter, presumably due to low flow rates. In order to accurately measure flow rates we would have liked to perform serial flow volume loops as described by Miller and Hyatt, ${ }^{7}$ but in view of the near exhaustion of the patient we felt these could not be justified. The improvement in $\mathrm{PaO}_{2}$ may be accounted for by an improvement in ventilation perfusion ratios and by the less dense mixture leading to a decrease in the work of breathing resulting in a decreased oxygen consumption and therefore an increased mixed venous oxygen content.

The management of patients with a compromised airway is discussed in current anaesthetic tests. ${ }^{8}$ Techniques recommended include awake intubation, inhalation induction, and tracheostomy under local anaesthesia. The latter was impossible because of the size and position of the mass. We considered an inhalation induction imprudent because the voluntary splinting with the accessory muscles of respiration was contributing significantly to the maintenance of the airway. Therefore, awake intubation was performed with helium available as a carrier gas to alleviate the patient's discomfort prior to induction of anaesthesia and in readiness should airway collapse and obstruction occur on emergence from anaesthesia. The patient's vocal cords were easily visualized and allowed free passage of a $7.0 \mathrm{~mm}$ endotracheal tube. It was surprising that the tube was so readily advanced through the narrowed trachea and we can only assume that the armoured tube was sufficiently rigid to distend this area without causing trauma.

The efficacy of helium-oxygen mixtures in large airway obstruction has been reported previously $y^{5,6}$ and Duncan ${ }^{6}$ suggested that theoretically this mixture might be of greater value in the small child than in the adult. This patient improved dramatically with helium, eliminating the need for emergency surgery, but it must be cautioned that helium as a carrier gas is effective only if turbulent flow conditions exist and that its concentration should be adjusted to maintain adequate oxygenation along with improvement in other measured variables. It must also be noted that despite marked patient improvement on spontaneously inspiring low den- sity gas mixtures, one must be prepared to perform rigid bronchoscopy or sternal split during induction of anaesthesia for surgical procedures related to airway compression.

\section{References}

1 MacIntosh R, Mushin WW, Epstein HG. Physics for Anaesthetists. 3rd ed. Oxford, Blackwell, $1963 ; 169$.

2 Reynolds $O$. Phil Trans, 1883, 174: 935-82 from MacIntosh et al., Physics for the Anaesthetist, 3rd ed., Oxford, Blackwell, 1963; 191.

3 Radford EP Jr, Ferris BG Jr, Kriete BC. Clinical use of a nomogram to estimate proper ventilation during artificial respiration. N Engl J Med 1954; 251: 877-8.

4 Benumoff $J L$, Alfery $D D$. Anesthesia for thoracic surgery. In: Miller, RD, (Ed.) Anesthesia, 2nd ed., Churchill Livingstone 1985: 1444.

5 Lu TS, Ohmura A, Wong KC, Hodges MR. Helium oxygen in treatment of upper airway obstruction. Anesthesiology 1976; 45: 678-81.

6 Duncan $P G$. Efficacy of helium-oxygen mixtures in the management of severe viral and post-intubation croup. Can Anaesth Soc J 1979; 26: 206-12.

7 Miller RD, Hyatt E. Evaluation of obstructing lesions of the trachea and larynx by flow-volume loops. Am Rev Respir Dis 1973; 108: 475-81.

8 Donlin JV Jr. Anesthesia eye, ear, nose, and throat surgery. In: Miller, RD, (Ed.) Anesthesia. New York: Churchill Livingstone. 1974: 1310-16.

\section{Résumé}

La conduite devant une obstruction des voies aêriennes secondaire à une masse thyroidienne est décrite. Quand la patiente respirait de l'air il apparaissait une détresse respiratoire sévère cependant lorsqu' elle inspirait un mélange de 22 pour cent d'axygène et helium elle notait presqu' instantanément un soulagement avec une diminution marquée de la fréquence respiratoire et une augmentation de volume courant et de la tension oxygène artérielle. Cette amélioration était prévisible car pour des situarions où le fot turbulant prédomine unte diminution de la densité des gaz inspirés provoquera une augmentation du flot. Contrairement au dogme dëjà établi une amélioration marquée était soutenue lorsque la patiente respirait un mélange de 50 pour cent oxygène et helium. La concentration d'oxygène et helium était ajustée afin d'obtenir un soulagement subjectif et une oxygénation adéquate. 